This is peer-reviwed version of the following article:

Stasić, J.; Selaković, N.; Puač, N.; Miletić, M.; Malović, G.; Petrović, Z. L.; Veljović, Đ.; Miletić, V. Effects of Non-Thermal Atmospheric Plasma Treatment on Dentin Wetting and Surface Free Energy for Application of Universal Adhesives. Clinical Oral Investigations 2019, 23 (3), 1383-1396. https://doi.org/10.1007/s00784-018-2563-2

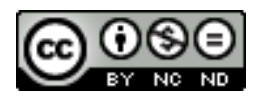

This work is licensed under a Creative Commons - Attribution-Noncommercial-No Derivative Works 3.0 Serbia 
Effects of non-thermal atmospheric plasma treatment on dentin wetting and surface free energy for application of universal adhesives

\section{Jovana N. Stasic ${ }^{1}$, Nenad Selaković², Nevena Puač², Maja Miletić ${ }^{3}$, Gordana Malović ${ }^{2}$, Zoran Lj.} Petrović ${ }^{2}$, Djordje N. Veljovic ${ }^{4}$, Vesna Miletic ${ }^{1, *}$

${ }^{1}$ University of Belgrade, School of Dental Medicine, DentalNet Research Group, Rankeova 4, 11000 Belgrade, Serbia

${ }^{2}$ University of Belgrade, Institute of Physics, Laboratory for gaseous electronics, Pregrevica 118, 11000 Belgrade, Serbia

${ }^{3}$ University of Belgrade, School of Dental Medicine, Department of Pathophysiology, Dr Subotica 1, 11000 Belgrade, Serbia

${ }^{4}$ University of Belgrade, Faculty of Technology and Metallurgy, Karnegijeva 4, 11120 Belgrade, Serbia

\section{Corresponding author}

Vesna Miletic

University of Belgrade, School of Dental Medicine, DentalNet Research Group

Rankeova 4, 11000 Belgrade, Serbia

Email: vesna.miletic@stomf.bg.ac.rs

Phone: +381117857051

\section{Acknowledgements}

This work was supported by the Ministry of Education, Science and Technological Development, Republic of Serbia [grant numbers III41011, ON171037 and ON172007]. The authors wish to thank 3M ESPE and Kuraray Noritake for a generous donation of materials used in this study. We would like to thank Dr. Djordje Antonijević for his assistance with SFE calculation. 


\title{
Effects of non-thermal atmospheric plasma treatment on dentin wetting and surface free energy for application of universal adhesives
}

\begin{abstract}
Objectives: To evaluate the effects of non-thermal atmospheric plasma (NTAP) treatments on dentin wetting and surface free energy (SFE) and compare the effects of NTAP treatment, etch-and-rinse and self-etch protocols for application of universal adhesives.

Materials and methods: Mid-coronal dentin of intact third molars was used to measure contact angles of distilled water, ethylene-glycol and diiodomethane and calculate SFE following different NTAP preset treatments (feeding gas consisting of pure $\mathrm{He}, \mathrm{He}+1 \% \mathrm{O}_{2}, \mathrm{He}+1.5 \% \mathrm{O}_{2}$ ), power input (1W or $3 \mathrm{~W})$ and tip-to-surface distance $(2,4$ or $8 \mathrm{~mm})$. Contact angles of reference liquids and SFE of dentin following $\mathrm{He}+1.5 \% \mathrm{O}_{2}$ at $3 \mathrm{~W}$ and $4 \mathrm{~mm}$ treatment was compared to phosphoric acid etching. Contact angles of Single Bond Universal (SBU; 3M ESPE) and Clearfil Universal Bond (CUB; Kuraray Noritake) were measured following NTAP, etch-and-rinse and self-etch protocols.

Results: NTAP significantly reduced contact angles of reference liquids and increased dentin SFE compared to untreated dentin $(p<0.05) . \mathrm{O}_{2}$ intensified the effect of He NTAP $(p<0.05)$. NTAP and phosphoric acid increased dentin polarity and Lewis base surface characteristics. Phosphoric acid increased contact angles of adhesives compared to the self-etch protocol $(p<0.05)$. NTAP resulted in lower adhesive contact angles than phosphoric acid, the difference being statistically significant for CUB $(p<0.05)$. Compared to the self-etch protocol, NTAP slightly reduced CUB contact angle but not that of SBU $(p>0.05)$.
\end{abstract}

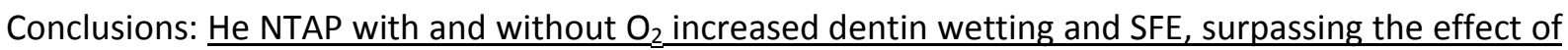
phosphoric acid and lowering adhesive contact angles. NTAP produced no apparent micromorphological changes on dentin surface comparable to acid etching.

Clinical significance: NTAP treatment of dentin prior to adhesive application increases dentin wetting and surface free energy facilitating better adhesive distribution on dentin surface compared to phosphoric acid etching and similar to the 'self-etch' application protocol.

Keywords: contact angle, dentin, non-thermal atmospheric plasma, surface free energy, universal adhesive, wetting 


\section{Introduction}

Current concepts of dentin adhesion include 'etch-and-rinse' (ER) or 'self-etch' (SE) approaches. An ER approach consists of etching dentin with $32-37 \%$ phosphoric acid to remove the smear layer, demineralize superficial dentin, expose the ultrafine collagen mesh and open dentinal tubules for subsequent adhesive penetration [1]. An SE approach excludes phosphoric acid step and instead relies on acidic monomers in dental adhesive formulation to partially demineralize dentin surface [2].

Universal adhesives, a recently marketed group of dental adhesives, are recommended for adhesion to dental tissues following either approach as well as to materials for indirect restorations without separate priming, hence the term 'universal'. Despite reports favoring the SE approach $[3,4]$, the manufacturers' recommendations leave it up to the practicing dentist to choose a preferable application strategy for universal adhesives suggesting that both ER and SE are likely used in current dental practice.

Surface modification by phosphoric acid etching has long been the preferred method of choice for optimizing dentin adhesion, though more complex than that on enamel. The effects of phosphoric acid on dentin are well known from the micro-morphological point of view [1]. However, the reported effects of acid etching on physico-chemical surface characteristics of dentin are contradictory. Attal et al. [5] concluded that acid etching results in a hydrophobic dentin surface while other authors reported increased hydrophilicity of dentin surface $[6,7]$.

Non-thermal atmospheric plasma (NTAP) is another powerful surface modification tool recently gaining momentum in adhesive dentistry research. NTAP is widely used in material engineering, production of semiconductor devices, integrated circuits, solar cells, etc. [8-11]. In case of biomedical applications NTAP may be used for treatment of heat-sensitive samples that cannot withstand vacuum. Also, NTAP or plasma liquid interactions is becoming great interdisciplinary area of research [12]. NTAPs are known for high amounts of reactive oxygen and nitrogen species (RONS) responsible for plasma interactions with biological samples [13-15]. In this paper, as an NTAP source we used a plasma needle constructed and developed in Laboratory for gaseous electronics, Institute of Physics Belgrade, Serbia. The plasma needle was previously used to enable an osteogenic differentiation of human periodontal ligament mesenchymal stem cells (hPDL-MSCs) that can help in cell-based treatment of periodontal defects [16], decontamination of bacteria in planktonic samples and biofilms [17-19] and the damage effect of plasma treatment was compared to the effects of ionizing radiation through induced DNA damage [20]. 
Literature review on NTAP in adhesive dentistry shows that NTAP was previously used to modify surfaces of dental tissues and restorative materials, induce resin polymerization and facilitate resin penetration and grafting onto collagen [21]. More specifically, NTAP was shown to substantially decrease water contact angles on dentin [22-24] with atomic compositional changes in the form of decreased percentage of $\mathrm{C}$ and $\mathrm{N}$ and increased $\mathrm{O}, \mathrm{Ca}$ and $\mathrm{P}$ [22]. Similar effects of NTAP on water contact angles were observed on enamel [22, 25], composites [22] and ceramics [26-28], suggesting increased hydrophilicity of all these substrates. Argon NTAP increased surface free energy and wettability of root dentin following sodium hypochlorite irrigation [29]. A recent paper [30] found no significant changes in dentin-surface topography after NTAP treatment for clinically relevant times. However, more numerous resin tags and a thinner dentin hybrid layer were visible after NTAP treatment. Enzymatic activity of matrix metalloproteinases was dependent on the NTAP treatment time [30]. Previous studies offered inconsistent evidence on the effects of NTAP on adhesive bond strength to dentin warranting further research [23, 24, 30-34]. An insight into previous studies reveals a non-standardized approach to the use of NTAP with differences regarding carrier gas, power, time and distance between the plasma source and the treated substrate.

Wetting (wettability) indicates the ability of an adhesive to spread over dentin as a result of the balancing adhesive and cohesive forces. It further contributes to adhesive penetration into collagen interfibrillary spaces and dentinal tubules by capillary forces, thereby improving dentin hybridization as the primary mechanism of adhesion [5]. In dental research, wetting characteristics of a substrate (e.g. dentin) are commonly determined by measuring contact angles of water. Conclusions on adhesive-dentin interaction based only on water contact angles may underestimate the effects of a complex adhesive mixture of polar and apolar, hydrophilic and hydrophobic components. Taking into account polar and apolar interactions between the liquid and solid, surface free energy (SFE) allows better understanding of the nature of surface interactions between adhesives and dentin.

The aims of this study were to: (1) compare the effects of a range of NTAP treatments on wetting and SFE of dentin and (2) compare a selected, most efficient NTAP treatment with ER and SE application protocols for universal adhesives in terms of wetting and SFE of dentin. The following working hypotheses were tested: (1) reduced distance, increased power and $\mathrm{O}_{2}$ feed in NTAP reduce the contact angles of reference liquids and increase SFE of dentin and (2) compared to ER and SE application protocols, an NTAP treatment results in lower contact angles of reference liquids and universal adhesives and higher SFE of dentin. 


\section{Materials and methods}

\subsection{Sample preparation}

A total of $\underline{278}$ human, intact, third molars extracted for orthodontic reasons were used in this study. Ethics Committee of the University of Belgrade, School of Dental Medicine approved (Approval No. 36/16) of the use of such teeth in research purposes and teeth were collected with patients' consent. Following extraction, the teeth were cleaned of debris, stored in $0.2 \%$ thymol in a refrigerator at $+4^{\circ} \mathrm{C}$ and used within 3 months of extraction.

Each tooth was embedded in super-hard gypsum up to the enamel-cementum junction. The cusps were cut off using a slow-speed diamond saw (Isomet 4000, Buehler, Lake Bluff, IL, USA) to expose flat dentin mid-coronally. A second cut was made $1 \mathrm{~mm}$ below the exposed dentin surface, producing a 1 $\mathrm{mm}$ thick dentin disk, one from each crown/tooth. Dentin disks were wet-polished manually with a 600-grit SiC abrasive paper for 30 s to produce a smear layer.

All dentin disks were allocated to groups and subgroups according to the subsequent treatment and reference liquids used for contact angle measurement, as shown in Table 1. Based on the results for $100 \%$ He NTAP, $8 \mathrm{~mm}$ tip-to-surface distance was not tested with NTAP with $\mathrm{O}_{2}$ feed to reduce the overall number of groups. Additional disks were prepared for SEM analysis.

\subsection{Non-thermal atmospheric plasma (NTAP) treatment}

An NTAP source used in this work was the so-called plasma needle [35] which generated non-thermal plasma at $13.56 \mathrm{MHz}$ frequency (Figure 1). The powered electrode of plasma needle was wolfram wire (outer diameter (o.d.) $0.5 \mathrm{~mm}$ ) enclosed in a ceramic tube. Both were placed within a glass tube with an inner diameter of $4 \mathrm{~mm}$ (outer diameter (o.d.) $6 \mathrm{~mm}$ ). The glass tube was held in Teflon support. In all experiments, we used helium or a mixture of helium and oxygen as the carrier gas and gas flow was kept constant at $1 \mathrm{slm}$ (standard liter per minute). We used pure $\mathrm{He}, 99 \% \mathrm{He}+1 \% \mathrm{O}_{2}$ or $98.5 \% \mathrm{He}+1.5 \%$ $\mathrm{O}_{2}$ mixtures. The distances between the treated dentin surface and the tip of the plasma needle were 2, 4 or $8 \mathrm{~mm}$. The applied powers of plasma needle in this experiment were $1 \mathrm{~W}$ or $3 \mathrm{~W}$. NTAP treatment time was $30 \mathrm{~s}$ in all groups. In order to determine the power delivered to the plasma we used derivative probes developed at the Laboratory for gaseous electronics, Institute of Physics Belgrade, Serbia [36]. 


\subsection{Acid etching and adhesive application}

To simulate the ER adhesive application protocol, the upper surface of each dentin disk was etched with 32\% phosphoric acid (Scotchbond Universal Etchant, 3M ESPE, St. Paul, MN, USA) for $15 \mathrm{~s}$, rinsed under tap water for $\underline{15} \mathrm{~s}$ and blot-dried using a cotton pellet (Agava, Prokuplje, Serbia).

To simulate the SE application protocol, dentin disks with the smear layer were blot-dried and used without any additional treatment. Table 2 provides details on the materials used in this study.

\subsection{Contact angle measurements and surface free energy calculation}

The sessile drop technique was used to measure contact angles of three reference liquids: distilled water, ethylene glycol (Sigma-Aldrich, St. Louis, MO, USA) and diiodomethane (Acros Organics, Fairlawn, NJ, USA). Following the ER and SE protocols, universal adhesives SBU and CUB were also used for contact angle measurements.

The experiment was so designed that NTAP treatment or acid etching and contact angle measurement were performed under the same temperature $\left(23.3 \pm 0.3^{\circ} \mathrm{C}\right)$ and humidity $(34.1$ physi $\% \pm 1.5 \%)$ conditions. Immediately after NTAP or acid etching treatment, the samples were transferred onto the contact angle measurement bench, so they remained still partially wet. A pre-set amount of liquid $(2 \mu l)$ was dispensed from a micropipette (BIOHIT, BiohitOyj, Helsinki, Finland) onto dentin surface at a $90^{\circ}$ angle and $4 \mathrm{~mm}$ distance. The contact angles $(\theta)$ of reference liquids and universal adhesives were

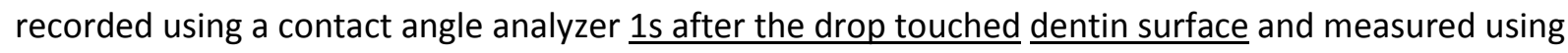
Image J software (Version 1.42, National Institute of Health, USA). Contact angle analyzer was constructed at the Institute of Physics to allow the above mentioned standard conditions (Figure 2). The setup included a DSLR Nikon D7100 camera with mounted Nikkor Macro lens $105 \mathrm{~mm}$ f2.8 D, Nikon $\underline{\text { SB910 flashlight and position stand. Camera in relation to the sample was adjusted using a tripod with }}$ built-in libel so it was always in the horizontal plane with the sample holder.

SFE $(\gamma)$ calculation was based on van Oss-Chaudhury-Good thermodynamic approach for solids and the three-liquid phase method. According to this theory, both apolar and polar interactions occur at the interface between liquid and solid materials [37]. Apolar interactions occurring between two completely apolar compounds are known as Lifshitz-van der Waals interactions. A component of SFE of compound $i$ based on strictly apolar interactions is expressed as Lifshitz-van der Waals component or $\gamma_{i}^{L W}$. Polar interactions are largely based on hydrogen-bonding or electron acceptor-electron donor (Lewis acid-base) interactions between polar moieties. These Lewis acid-base interactions are asymmetrical, so electron acceptor and electron donor parameters of the polar component of SFE of compound $i$ are expressed as $\gamma_{i}^{+}$and $\gamma_{i}^{-}$[37]. SFE of a solid $\left(\gamma_{S}\right)$ and its components (apolar $\gamma_{S}^{L W}$, Lewis 
acid $\gamma_{S}^{+}$and Lewis base $\gamma_{S}^{-}$) are calculated using the contact angles $(\theta)$ of three reference liquids with their known SFE parameters $\left(\gamma_{L}^{L W}, \gamma_{L}^{+}\right.$and $\left.\gamma_{L}^{-}\right)$according to the following formula:

$(1+\cos \theta) \gamma_{L}=2\left(\sqrt{\gamma_{S}^{L W} \gamma_{L}^{L W}}+\sqrt{\gamma_{S}^{+} \gamma_{L}^{-}}+\sqrt{\gamma_{S}^{-} \gamma_{L}^{+}}\right)$

where the SFE of liquid equals the sum of SFE components (apolar Lifshitz-van der Waals and polar acid-base) according to the rule of additivity:

$\gamma_{L}=\gamma_{L}^{L W}+\gamma_{L}^{A B}$

with $\gamma_{L}^{A B}=2 \sqrt{\gamma_{L}^{+} \gamma_{L}^{-}}$

By solving the van Oss-Chaudhury-Good equation three times for three reference liquids, it is possible to differentiate between polar and apolar surface interactions and between Lewis acid and Lewis base polar interactions of a tested solid. Though reference liquids may vary, two of them must be polar [37]. $\underline{\text { In the present study, water and ethylene glycol were used as polar and diiodomethane as apolar liquid }}$ with known SFE parameters [38, 39].

\subsection{Scanning Electron Microscopy (SEM)}

Representative samples from NTAP, acid etched and control groups (8 teeth in total) were subjected to SEM to analyze the differences in surface micro-morphology. Without prior dehydration treatment, the samples were mounted on aluminum stubs, fixed with graphite conductive tape, subjected to vacuum in a sputter coater (POLARON SC502, Fisions Instruments, Ipswich, UK) and then coated with a thin film of Au alloy. The samples were analyzed using TESCAN FE-SEM (Mira 3 XMU, TESCAN a.s., Brno, the Czech Republic) operating at $10 \mathrm{keV}$.

\subsection{Statistical analysis}

All data were statistically analyzed in Minitab 16 software package (Minitab Inc., State College, PA, USA) with the level of significance set at 0.05 . To test the differences in contact angles for each reference liquid, general linear model (GLM) was applied for factors 'plasma', 'power' and 'distance' as well as their interactions. To test the differences in dentin SFE, GLM was applied using the same factors. Where the interaction was significant, further one-way analysis of variance (ANOVA) with Tukey's post-hoc test and Bonferroni correction was used. Differences in contact angles and SFE between the selected NTAP treatment, ER and SE protocols were tested using one way ANOVA with Tukey's post-hoc test. Equal variances were tested using Bartlett's and Levene's tests and where 
necessary data transformation was applied to stabilize the differences in variances. Quadratic, logarithmic or sqrt functions were used for data transformation.

\section{Results}

\subsection{Screening of NTAP treatment regimes}

Figures 3 present the box-an-whisker plots of contact angles of reference liquids following an array of NTAP treatments. GLM analyses showed that all NTAP treatments significantly reduced the contact angles of all three reference liquids compared to the untreated control group $(p<0.001)$. The results were most prominent for water with contact angles decreasing from $84.2^{\circ} \pm 2.6^{\circ}$ in the control group to the range of $6-30^{\circ}$ in the NTAP-treated group with the exception of $100 \%$ He_1W_8mm group (where the post-treatment contact angle was $69.1^{\circ} \pm 5.6^{\circ}$ ). Though contact angles for ethylene-glycol and diiodomethane were similar in the control group $\left(36.6^{\circ} \pm 5.3^{\circ}\right.$ and $37.9^{\circ} \pm 1.9^{\circ}$, respectively), NTAP treatment decreased the ethylene glycol contact angle $\left(5-12^{\circ}\right.$ range) to a greater extent than that of diiodomethane $\left(10-30^{\circ}\right.$ range).

GLM analyses for factors 'plasma', 'power' and 'distance' showed that $\mathrm{O}_{2}$ feed further decreased contact angles of water compared to pure He NTAP $(p<0.001)$. There was no difference between $1 \%$ and $1.5 \% \mathrm{O}_{2}$ in the resulting contact angles of water. Such effects of NTAP with $\mathrm{O}_{2}$ feed were not observed with ethylene-glycol and diiodomethane ( $p=0.183$ and $p=0.094$, respectively).

NTAP power of $3 \mathrm{~W}$ significantly reduced contact angles of water and diiodomethane as compared to $1 \mathrm{~W}$ power $(\underline{p<0.001})$ but this effect was not found for ethylene glycol $(\underline{p=0.008)}$. Tip-to-surface distances of 2 and $4 \mathrm{~mm}$ did not produce any significant differences in contact angles of reference liquids (water $p=0.068$; ethylene glycol $p=0.109$ and diiodomethane $p=0.454$ ). For $8 \mathrm{~mm}$ distance, $100 \%$ He NTAP at $1 \mathrm{~W}$ resulted in significantly higher water contact angles than other groups $(p<0.001)$. Therefore, we excluded $8 \mathrm{~mm}$ tip-to-surface distance from the NTAP treatments with $\mathrm{O}_{2}$ feed. Within group differences were detected using one-way ANOVAs statistical test and are marked with letters and symbols in Figures 3.

Regarding SFE, significantly higher SFE of NTAP-treated dentin was found than that of the untreated group (Figure 4). Moreover, NTAP with $\mathrm{O}_{2}$ feed further increased the SFE of dentin compared to $100 \%$ He NTAP $(\underline{p<0.001})$. No differences were found between NTAPs with $1 \%$ and $1.5 \% \mathrm{O}_{2}(\underline{p=0.357})$.

For the same NTAP source, higher SFE of dentin was associated higher power for pure $\mathrm{He}$ and $\mathrm{He}+1 \mathrm{OO}_{2}$ NTAPs i.e. $3 \mathrm{~W}$ resulting in higher SFE than $1 \mathrm{~W}$ treatment $(p<0.001)$. Conversely, different powers of 
NTAP with $1.5 \% \mathrm{O}_{2}$ feed had no effect on the SFE of dentin $(p=0.09)$, except for $1 \mathrm{~W} 4 \mathrm{~mm}$ group which resulted in slightly lower SFE of dentin compared to $3 \mathrm{~W} 4 \mathrm{~mm}(p=0.013)$.

In general, the tip-to-surface distance did not affect the SFE of NTAP-treated dentin $(\underline{p=0.514})$, with exceptions being $100 \% \mathrm{He} \_1 \mathrm{~W} \_8 \mathrm{~mm}$ and $\mathrm{He}+1.5 \% \mathrm{O}_{2} \_1 \mathrm{~W} \_4 \mathrm{~mm}$, which showed significantly lower SFE than their corresponding groups ( $p<0.001$ and $p=0.007$, respectively) (Figure 4).

Component analysis of SFE is presented in Figure 5. In the control group (untreated dentin), apolar component of SFE appeared more prominent than the polar component, of which Lewis acid was predominant. NTAP treatments, except for the less effective $1 \mathrm{~W} \_8 \mathrm{~mm}$ of pure He NTAP, all showed rather similar effects i.e. polar component substantially increased compared to the control, and apolar component also slightly increased. Within the polar component of SFE in NTAP-treated dentin, Lewis base surpassed Lewis acid component. Compared to the control untreated dentin, Lewis base and apolar components increased whereas Lewis acid component decreased.

\subsection{Comparison of NTAP with ER and SE protocols for universal adhesives}

Based on the previous screening, the following NTAP treatment was chosen for the next part of the study: $\mathrm{He}+1.5 \% \mathrm{O}_{2} \_3 \mathrm{~W} \_4 \mathrm{~mm}$. Contact angle measurements for three reference liquids and the subsequent SFE calculation were performed for NTAP-treated, acid-treated and untreated dentin. Universal adhesives SBU and CUB were used only to measure their contact angles on NTAP-treated, acid-treated and untreated dentin. It was not possible to calculate the SFE of dentin using adhesives as SFE may only be calculated using reference liquids (water, ethylene glycol and diiodomethane).

Contact angles of all reference liquids were lower on NTAP-treated than on acid-treated or untreated dentin $(p<0.001)$ (Figure 6). Phosphoric acid etching produced significantly lower water contact angles compared to the untreated, control group $(p<0.001)$ but the same effect was not found for ethyleneglycol and diiodomethane ( $p=0.069$ and $p=0.120$, respectively).

As for universal adhesives, higher contact angles of SBU and CUB $\left(44.13 \pm 8.45^{\circ}\right.$ and $33.04 \pm 6.04^{\circ}$, respectively) were found on acid-treated than untreated dentin $\left(29.94 \pm 1.86^{\circ}\right.$ and $26.56 \pm 2.33^{\circ}$,

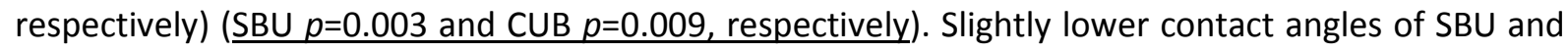
CUB were measured on NTAP-treated dentin $\left(35.68 \pm 2.35^{\circ}\right.$ and $19.96 \pm 6.89^{\circ}$, respectively) compared to acid-etched dentin, but the differences reached statistical significance only for CUB ( $p=0.015)$. NTAPtreated and untreated dentin showed no significant differences in contact angles of universal adhesives $(\underline{p=0.808})$. 
The SFE of dentin was highest on NTAP-treated and lowest on untreated dentin. (Figure 7). NTAP and untreated dentin. NTAP increased and acid etching decreased apolar component of SFE compared to that of untreated dentin.

\subsection{SEM micro-morphological analysis}

Representative SEM micrographs are presented in Figure 8. Phosphoric acid etching removed the smear layer, exposed the collagen mesh and opened dentinal tubules. No visible micro-morphological differences were found between NTAP-treated and untreated dentin (control group) which was only ground with 600-grit SiC abrasive paper to produce the smear layer.

\section{Discussion}

The first working hypothesis was upheld i.e. all NTAP regimes reduced contact angles of reference liquids and increased SFE of dentin compared to the untreated dentin with further detectable differences relative to the tip-to-surface distance, power and $\mathrm{O}_{2}$ feed.

He and Ar are commonly used carrier gases in NTAP studies on dental tissues with powers generally higher $(5-10 \mathrm{~W}$ ) than in the present study ( $1 \mathrm{~W}$ and $3 \mathrm{~W}$ ). A comparable power of 2-3 W was used in the study by Zhang et al. [40] who used Ar-based NTAP to study adhesive penetration into demineralized dentin. Our intention was to optimize He-based NTAP regimes with lower powers for use on dentin in order to minimize the effect of heating and potential dentin cracks observable with higher powered NTAPs. Furthermore, the chosen time and tip-to-surface distances are clinically relevant and manageable. Up to $10 \% \mathrm{O}_{2}$ feed was added to NTAPs used for microbial disinfection [41] whereas lower, up to $1 \%, \mathrm{O}_{2}$ was added to NTAP for dentin and root canal treatment [42]. We used $1 \%$ and $1.5 \% \mathrm{O}_{2}$ feed to investigate if slightly higher $\mathrm{O}_{2}$ feed would intensify the effect of NTAP. The results indicated that whilst $\mathrm{O}_{2}$ generally intensified the effects of NTAP on wetting and SFE of dentin, there was little or no difference between $1 \%$ and $1.5 \% \mathrm{O}_{2}$ suggesting that there may be a 'saturation' effect of $\mathrm{O}_{2}$ feed in NTAP. In the study of Koban et al. [42] significant differences in water contact angles were found between Ar NTAP with $0.2 \%$ and $1 \% \mathrm{O}_{2}$. These findings indicate that $\mathrm{O}_{2}$ feed as low as $0.2 \%$ may be disregarded and pure carrier gas used for plasma treatment. If $\mathrm{O}_{2}$ is to be added to NTAP, the present results suggest that $1-1.5 \% \mathrm{O}_{2}$ may be recommended.

All NTAP regimes significantly reduced the contact angles of reference liquids, especially water, and increased SFE of dentin compared to the untreated dentin, indicating a dramatic increase in dentin wetting. The finding of lower contact angles of reference liquids was expected and is in accord with previous studies [22-25]. Moreover, the same effects were achieved in the present study with lower 
powered NTAPs $(1 \mathrm{~W})$ at clinically relevant distances that allow focusing the NTAP needle on small cavities, e.g. 'slot', Class III and V and minimally invasive Class I cavities.

A significant decrease in water contact angle was coupled with a greater decrease in the contact angle of ethylene glycol than diiodomethane. NTAP induced a greater change with polar substances (water and ethylene glycol) than apolar diiodomethane suggesting that a major change on dentin surface was related to hydrophilic and polar interactions. This finding was corroborated by the SFE component analysis, in which polar component increased substantially following the NTAP treatment. A change in acid-base interaction was also detected following the NTAP treatment with an increase in Lewis base component. This further suggests that more negatively charged sites appear on the surface of the NTAP-treated dentin for potential interactions with electron accepting molecules, such as acidic monomers from adhesives.

Our SFE component analyses is in accordance with previous spectroscopic (XPS and FTIR) studies which reported grafting polar, oxygen-containing moieties on NTAP-treated surfaces as a result of an intense attack of reactive oxygen species. Namely, Chen et al. [22] found an increased percentage of $O$ in dentin and enamel, Ritts et al. [32] found increased carbonyl C=O groups on collagen and Lehmann et al. [25] reported on increased carboxylate $\mathrm{CO}^{2-}$ and carbonate $\mathrm{CO}_{3}{ }^{2-}$ ions on the surface of enamel. Beside negatively charged ions with clear affinity for reaction with Lewis acids (electron acceptors), $\mathrm{C}=\mathrm{O}$ group also contributes to surface reactivity. $\mathrm{C}=\mathrm{O}$ group is moderately polar, considering the differences in electronegativities of $C$ and $O$, with affinity for interactions between $O$ and Lewis acids/electron acceptors (e.g. $\mathrm{H}^{+}$) or $\mathrm{C}$ and Lewis bases/electron donors (e.g. $\mathrm{NH}_{3}$ or $\mathrm{OH}^{-}$). The present results suggest that $\mathrm{O}_{2}$ feed in NTAP further increases polar, specifically Lewis base, interaction sites compared to pure He NTAP. Higher powered NTAPs further intensified this effect of $\mathrm{O}_{2}$ feed.

Based on the screening of an array of NTAP treatments, we chose $\mathrm{He}+1.5 \% \mathrm{O}_{2}$ NTAP at $3 \mathrm{~W}$ power and $4 \mathrm{~mm}$ tip-to-surface distance as the NTAP treatment in the second part of the study. Here we compared the effects of the said NTAP treatment with phosphoric acid etching representing the ER protocol and no treatment representing the SE protocol of adhesive application. Two universal adhesives were chosen, SBU and CUB. According to manufacturers' technical data sheets, both SBU and CUB are ethanol- and water-based adhesives, containing BisGMA, HEMA and 10-MDP monomers. CUB is claimed to contain a highly hydrophilic acidic amide monomer for improved wetting and adhesive penetration, yet the manufacturer did not disclose its name and chemical structure.

The second working hypothesis was partially upheld as NTAP induced greater SFE of dentin and lower contact angles of reference liquids compared to phosphoric acid etching (ER protocol) but had a limited effect on universal adhesives in relation to the SE application protocol. 
The results showed that both NTAP and phosphoric acid significantly increase wetting of the treated glycol and diiodomethane contact angles were not significantly different from those on untreated dentin. Increased wetting of dentin surface following phosphoric acid etching is in accordance with previous studies [6, 7]. Furthermore, our SFE component analysis revealed that untreated dentin exhibited both apolar and polar sites with predominant Lewis acid electrostatic component. As is customary in dental studies, the 'untreated' dentin refers to mid-coronal dentin cut with a diamond saw and ground with 600-grit SiC abrasive paper to produce a smear layer of various thicknesses. Thus, surface characteristics relate to the smear layer which is essentially an amorphous layer of inorganicorganic debris containing hydroxyapatite, collagen and microbial remnants [43]. Electrostatic Lewis acidity of the dentin smear layer is likely associated with the abundance of $\mathrm{Ca}^{2+}$ ions from hydroxyapatite and contributes to the interaction of phosphate or carboxylate ions with the smear layer and dentin itself during acid etching with phosphoric acid or acidic monomers in adhesives.

Despite its effect on water, phosphoric acid etching significantly increased the contact angles of universal adhesives, SBU and CUB, compared to the untreated dentin where SBU and CUB were applied following the SE protocol. This finding highlights the importance of the present approach based on three reference liquids and SFE component analysis to elucidate the true interaction between adhesives and dentin. Though phosphoric acid etching increased surface hydrophilicity it did not contribute to wider adhesive distribution over etched dentin compared to adhesive distribution on unetched dentin. This could be due to the presence of hydrophobic monomers in both adhesives, namely BisGMA, and the subsequent phase separation between hydrophobic and hydrophilic monomers within the hybrid layer $[44,45]$. Phosphoric acid etching decreased the apolar component of dentin SFE further contributing to the depleted interaction between apolar adhesive components and dentin surface. Though ether (R-O-R) and hydroxyl (R-OH) linkages in monomers exert some polarity, the majority of spacer groups in hydrophobic monomers contribute to low polarity or apolarity [46]. Slightly decreased apolar component of SFE could explain why the only apolar reference liquid, diiodomethane, exerted increased contact angle on acid etched dentin.

Both NTAP and phosphoric acid etching resulted in an increase of electrostatic Lewis base component. Increased grafting of polar, oxygen-containing groups was previously discussed for NTAP treatment. As for acid etching, Lehmann et al. [25] detected $\mathrm{C}=\mathrm{O}$ groups and $\mathrm{CO}^{2-}$ and $\mathrm{CO}_{3}{ }^{2-}$ ions at enamel surface following acid etching using XPS analysis. A similar increase in polar, oxygen-containing moieties at dentin following acid etching could be the reason for increased Lewis base sites as found in the present 
study. This may favor the subsequent interaction of electron acceptors, or Lewis acids, and contribute to hydrogen bonding between adhesive resins and dentin substrate.

NTAP treatment of dentin prior to adhesive application resulted in lower contact angles of SBU and CUB adhesives compared to those on the acid etched dentin, suggesting better adhesive distribution following NTAP treatment. A more favorable effect of NTAP than phosphoric acid in terms of adhesive distribution could be due to the increased surface reactivity of dentin as indicated by increased both apolar and polar (Lewis acid and Lewis base) interaction sites.

Increased surface reactivity and hydrophilicity are likely reasons for lower contact angles of CUB adhesive on NTAP-treated than untreated dentin. The presence of a hydrophilic amide dimethacrylate monomer in CUB, in addition to hydrophilic HEMA, may have contributed to this finding. The effect of NTAP on adhesive contact angle appeared to be material-dependent as NTAP did not facilitate the distribution of SBU adhesive compared to the untreated dentin as it did with CUB. Further research is therefore required to elucidate the adhesive-dentin interactions following NTAP treatment.

Though positive effects of NTAP on adhesive penetration were documented, adhesive phase separation was found in NTAP-treated dentin in a previous study [40]. NTAP increased the penetration of hydrophilic but not hydrophobic monomers within the hybrid layer, limiting the positive effects of NTAP. Phase separation within the hybrid layer due to increased penetration of hydrophilic monomers increases the risk of creating areas more susceptible to water sorption, as hydrophilicity was found to be the prime factor determining the extent of water sorption $[47,48]$. In turn, water sorption promotes faster biodegradation of adhesive itself [48] as well as adhesive-dentin bond $[49,50]$. This could be the reason for the lack of long-term effect of NTAP on adhesive bond strength despite positive effects on immediate bond strength $[23,24,33,34,51,52]$.

The present qualitative SEM analysis revealed no micro-morphological differences between untreated and NTAP-treated dentin. Previous studies also reported no structural differences in the appearance of NTAP-treated dentin/enamel, hence no destructive effects of NTAP [22, 25, 42]. NTAP does have a potential not only to chemically interact with the surface but also to increase surface roughness of dentin by etching [21]. However, this roughening effect was not as notable as with phosphoric acid [25] due to the selective etching of the organic phase by NTAP and not the mineral phase, which was confirmed by elemental analysis [22]. Under the present experimental conditions, no etching effect of NTAP occurred on dentin surface. 


\section{Conclusion}

He NTAP with and without $\mathrm{O}_{2}$ substantially increased dentin wetting and SFE, surpassing the effect of phosphoric acid etching. $\mathrm{O}_{2}$ intensified the effect of He NTAP at $1 \mathrm{~W}$ and $3 \mathrm{~W}$ powers and clinically relevant distances of 2 and $4 \mathrm{~mm}$. Surface modification of dentin following NTAP treatment included increased hydrophilicity, polarity and electrostatic Lewis base interaction sites. Phosphoric acid etching did not favor adhesive distribution on dentin surface as indicated by increased contact angles of universal adhesives, SBU and CUB, despite decreasing water contact angle compared to the untreated dentin. NTAP treatment of dentin prior to adhesive application facilitated better adhesive distribution compared to acid etched dentin. However, NTAP did not show an improvement regarding the adhesive distribution on dentin compared to the SE protocol of application. Under the present conditions, the effects of NTAP were mainly related to surface modification, with no etching ability but also no structural damage on the dentin surface.

\section{Disclosure}

The authors declare no financial interest in any of the products used in the study.

\section{Compliance with ethical standards}

- Conflict of interest: Author Jovana N. Stasic declares that she has no conflict of interest. Author Nenad Selaković declares that he has no conflict of interest. Author Nevena Puač declares that she has no conflict of interest. Author Maja Miletić declares that she has no conflict of interest. Author Gordana Malović declares that she has no conflict of interest. Author Zoran Lj. Petrović declares that he has no conflict of interest. Author Djordje N. Veljovic declares that he has no conflict of interest. Author Vesna Miletic declares that she has no conflict of interest.

- Funding: The work was supported by the Ministry of Education, Science and Technological Development, Republic of Serbia [grant numbers III41011, ON171037 and ON172007].

- This article does not contain any studies with human participants or animals performed by any of the authors.

- Informed consent: For this type of study, formal consent is not required. 


\section{References}

1.Pashley DH, Tay FR, Breschi L, Tjäderhane L, Carvalho RM, Carrilho M, Tezvergil-Mutluay A (2011) State of the art etch-and-rinse adhesives. Dent Mater 27:1-16.

https://doi.org/10.1016/j.dental.2010.10.016

2.Van Meerbeek B, Yoshihara K, Yoshida Y, Mine A, De Munck J, Van Landuyt KL (2011) State of the art of self-etch adhesives. Dent Mater 27:17-28.

https://doi.org/10.1016/i.dental.2010.10.023

3.Rosa WL, Piva E, Silva AF (2015) Bond strength of universal adhesives: A systematic review and meta-analysis. J Dent 43:765-776.

https://doi.org/10.1016/i.jdent.2015.04.003

4.Zhang ZY, Tian FC, Niu LN, Ochala K, Chen C, Fu BP, Wang XY, Pashley DH, Tay FR (2016) Defying ageing: An expectation for dentine bonding with universal adhesives? J Dent 45:43-52.

https://doi.org/10.1016/j.jdent.2015.11.008

5.Attal JP, Asmussen E, Degrange M (1994) Effects of surface treatment on the free surface energy of dentin. Dent Mater 10:259-264.

http://dx.doi.org/10.1016/0109-5641(94)90071-X

6. Rosales JI, Marshall GW, Marshall SJ, Watanabe LG, Toledano M, Cabrerizo MA, Osorio R (1999)

Acid-etching and hydration influence on dentin roughness and wettability. J Dent Res 78:1554-1559. https://doi.org/10.1177/00220345990780091001

7.Toledano M, Osorio R, Perdigao J, Rosales JI, Thompson JY, Cabrerizo-Vilchez MA (1999) Effect of acid etching and collagen removal on dentin wettability and roughness. J Biomed Mater Res 47:198203.

https://doi.org/10.1002/(SICI)1097-4636(199911)47:2<198::AID-JBM9>3.0.CO;2-L

8. Makabe T, Petrovic ZLj (2001) Plasma Electronic, Second Editor: Application in Microelectronic Device. CRC Press, Taylor and Francis Group, Boca Raton

9. Adamovich I, Baalrud SD, Bogaerts A, Bruggeman PJ, Cappelli M, Colombo V, Czarnetzki U, Ebert U, Eden JG, Favia P, Graves DB, Hamaguchi S, Hieftje G, Hori M, Kaganovich ID, Kortshagen U, Kushner MJ, Mason NJ, Mazouffre S, Mededovic Thagard S, Metelmann H-R, Mizuno A, Moreau E, Murphy AB, Niemira BA, Oehrlein GS, Petrovic ZLj, Pitchford LC, Pu Y-K, Rauf S, Sakai O, Samukawa S, Starikovskaia S, Tennyson J, Terashima K, Turner MM, Van de Sanden MCM, Vardelle A (2017) The 2017 Plasma Roadmap: Low temperature plasma science and technology. J Phys D: Appl Phys 50:323001. https://doi.org/10.1088/1361-6463/aa76f5

10. Abe H, Yoneda M, Fujiwara N (2008) Developments of Plasma Etching Technology for Fabricating Semiconductor Devices. Japanese Journal of Applied Physics 47:1435-1455.

https://doi.org/10.1143/JJAP.47.1435

11. Chen FF (1995) Industrial applications of low-temperature plasma Physics. Physics of Plasmas 2:2164.

https://doi.org/10.1063/1.871477

12. Bruggeman PJ, Kushner MJ, Locke BR, Gardeniers JGE, Graham WG, Graves DB, Hofman-Caris RCHM, Maric D, Reid JP, Ceriani E, Fernandez Rivas D, Foster JE, Garrick SC, Gorbanev Y, Hamaguchi S, Iza F, Jablonowski H, Klimova E, Kolb J, Krcma F, Lukes P, Machala Z, Marinov I, Mariotti D, Mededovic Thagard S, Minakata D, Neyts EC, Pawlat J, Petrovic ZLj, Pflieger R, Reuter S, Schram D C, Schröter S, Shiraiwa M, Tarabová B, Tsai PA, Verlet JRR, Von Woedtke T, Wilson KR, Yasui K, Zvereva G (2016) Plasma-liquid interactions: a review and roadmap. Plasma Sources Sci Technol 25:053002. https://doi.org/10.1088/0963-0252/25/5/053002

13. Stoffels E, Kieft IE, Sladek REJ , Van den Bedem L J M, Van der Laan EP, Steinbuch M (2006) Plasma needle for in vivo medical treatment: recent developments and perspectives. Plasma Sources Sci Technol 15:S169.

https://doi.org/10.1088/0963-0252/15/4/S03 
14. Von Woedtke Th, Reuter S, Masur K, Weltmann KD (2013) Plasmas for medicine. Physics Reports 530:291-320.

https://doi.org/10.1016/i.physrep.2013.05.005

15. Puač N, Živković S, Selaković N, Milutinović M, Boljević J, Malović G, Petrović ZLj (2014) Long and short term effects of plasma treatment on meristematic plant cells. Appl Phys Lett 104:214106. https://doi.org/10.1063/1.4880360

16. Miletić M, Mojsilović S, Okić Đorđević I, Maletić D, Puač N, Lazović S, Malović G, Milenković $P$, Petrović ZLj, Bugarski D (2013) Effects of non-thermal atmospheric plasma on human periodontal ligament mesenchymal stem cells. Journal of Physics D: Applied Physics 46:345401. https://doi.org/10.1088/0022-3727/46/34/345401

17.Lazović S, Puač N, Miletić M, Pavlica D, Jovanović M, Bugarski D, Mojsilović S, Maletić D, Malović G, Milenković P, Petrović Z (2010) The effect of a plasma needle on bacteria in planktonic samples and on peripheral blood mesenchymal stem cells. New Journal of Physics 12:083037.

https://doi.org/10.1088/1367-2630/12/8/083037

18.Miletić M, Vuković D, Živanović I, Dakić I, Soldatović I, Maletić D, Lazović S, Malović G, Petrović ZLj, Puač N (2014) Inhibition of methicillin resistant Staphylococcus aureus by a plasma needle. Central European Journal of Physics 12:160-167. https://doi.org/ 10.2478/s11534-014-0437-z

19.Puač N, Miletić M, Mojović M, Popović-Bijelić A, Vuković D, Miličić B, Maletić D, Lazović S, Malović G, Petrović ZLj (2015) Sterilization of bacteria suspensions and identification of radicals deposited during plasma treatment. Open Chemistry 13:332-338.

https://doi.org/10.1515/chem-2015-0041

20.Lazović S, Maletić D, Leskovac A, Filipović J, Puač N, Malović G, Joksić G, Petrović ZLj (2014) Plasma induced DNA damage: Comparison with the effects of ionizing radiation. Appl Phys Lett 105:124101. https://doi.org/10.1063/1.4896626

21.Liu Y, Liu Q, Yu QS, Wang Y (2016) Nonthermal Atmospheric Plasmas in Dental Restoration. J Dent Res 95:496-505.

https://doi.org/10.1177/0022034516629425

22.Chen M, Zhang Y, Sky Driver M, Caruso AN, Yu Q, Wang Y (2013) Surface modification of several dental substrates by non-thermal, atmospheric plasma brush. Dent Mater 29:871-880.

https://doi.org/10.1016/j.dental.2013.05.002

23.Han GJ, Kim JH, Chung SN, Chun BH, Kim CK, Seo DG, Son HH, Cho BH (2014) Effects of nonthermal atmospheric pressure pulsed plasma on the adhesion and durability of resin composite to dentin. Eur J Oral Sci 122:417-423.

https://doi.org/10.1111/eos.12153

24. Hirata R, Teixeira H, Ayres AP, Machado LS, Coelho PG, Thompson VP, Giannini M (2015) Longterm Adhesion Study of Self-etching Systems to Plasma-treated Dentin. J Adhes Dent 17:227-233. https://doi.org/10.3290/i.jad.a34138

25.Lehmann A, Rueppell A, Schindler A, Zyla IM, Seifert HJ, Nothdurft F, Hannig M, Rupf S (2013) Modification of enamel and dentin surfaces by non-thermal atmospheric plasma. Plasma Processes Polym 10:262-270. https://doi.org/10.1002/ppap.201200088

26. Han GJ, Chung SN, Chun BH, Kim CK, Oh KH, Cho BH (2012) Effect of the applied power of atmospheric pressure plasma on the adhesion of composite resin to dental ceramic. J Adhes Dent 14:461-469. https://doi.org/10.3290/i.jad.a25688

27.Silva NR, Coelho PG, Valverde GB, Becker K, Ihrke R, Quade A, Thompson VP (2011) Surface characterization of Ti and Y-TZP following non-thermal plasma exposure. J Biomed Mater Res B Appl Biomater 99:199-206.

https://doi.org/10.1002/jbm.b.31887 
28.Valverde GB, Coelho PG, Janal MN, Lorenzoni FC, Carvalho RM, Thompson VP, Weltemann KD, Silva NR (2013) Surface characterisation and bonding of Y-TZP following non-thermal plasma treatment. J Dent 41:51-59.

https://doi.org/10.1016/j.jdent.2012.10.002

29.Prado Md, Roizenblit RN, Pacheco LV, Barbosa CA, Lima CO, Simão RA (2016) Effect of Argon Plasma on Root Dentin after Use of 6\% NaOCl. Braz Dent J 27:41-5.

https://doi.org/10.1590/0103-6440201600486

30. Ayres AP, Bonvent JJ, Mogilevych B, Soares LES, Martin AA, Ambrosano GM, Nascimento FD, Van Meerbeek B, Giannini M (2018) Effect of non-thermal atmospheric plasma on the dentin-surface topography and composition and on the bond strength of a universal adhesive. Eur J Oral Sci 126:5365.

\section{http://doi.org/10.1111/eos.12388}

31. Ayres APA, Pongprueksa P, De Munck J, Gré CP, Nascimento FD, Giannini M, Van Meerbeek B (2017) Mini-interfacial Fracture Toughness of a Multimode Adhesive Bonded to Plasma-treated Dentin. J Adhes Dent 19:409-416.

https://doi.org/10.3290/i.jad.a38999

32.Ritts AC, Li H, Yu Q, Xu C, Yao X, Hong L, Wang Y (2010) Dentin surface treatment using a nonthermal argon plasma brush for interfacial bonding improvement in composite restoration. Eur J Oral Sci 118:510-516.

https://doi.org/10.1111/j.1600-0722.2010.00761.x

33.Dong X, Ritts AC, Staller C, Yu Q, Chen M, Wang Y (2013) Evaluation of plasma treatment effects on improving adhesive-dentin bonding by using the same tooth controls and varying cross-sectional surface areas. Eur J Oral Sci 121:355-362.

https://doi.org/10.1111/eos.12052

34. Hirata R, Sampaio C, Machado LS, Coelho PG, Thompson VP, Duarte S, Ayres AP, Giannini M (2016) Short- and Long-term Evaluation of Dentin-Resin Interfaces Formed by Etch-and-Rinse Adhesives on Plasma-treated Dentin. J Adhes Dent 18:215-222.

https://doi.org/10.3290/i.jad.a36134

35. Lazović S, Puač N, Miletić M, Maletić D, Malović G, Mojsilović S, Milenković P, Petrović ZLj (2010) Plasma needle treatment of the human peripheral blood-derived multipotent mesenchymal stem cells (hPB-MSC). The 3rd IC-PLANTS 11-12. March 2010, Nagoya, Japan

36. Puač N, Petrović ZLj, Malović G, Dordević A, Živković S, Giba Z, Grubišić D (2006) Measurements of voltage-current characteristics of a plasma needle and its effect on plant cells. J Phys D: Appl Phys 39:3514-3519.

https://doi.org/10.1088/0022-3727/39/16/S09

37.Van Oss CJ, Chaudhury MK, Good RJ (1988) Interfacial Lifshitz-van der Waals and Polar Interactions in Macroscopic Systems. Chem Rev 88:927-941.

https://doi.org/10.1021/cr00088a006

38.Mittal KL (2009) Contact Angle, Wettability and Adhesion. Koninklijke Brill NV, Leiden 39.Starostina IA, Stoyanov OV, Deberdeev RY (2014) Polymer Surfaces and Interfaces: Acid-Base Interactions and Adhesion in Polymer-Metal Systems. Apple Academic Press, Toronto 40.Zhang Y, Yu Q, Wang Y (2014) Non-thermal atmospheric plasmas in dental restoration: improved resin adhesive penetration. J Dent 42:1033-1042.

https://doi.org/10.1016/i.jdent.2014.05.005

41.Chen W, Huang J, Du N, Liu XD, Wang XQ, Lv GH, Zhang GP, Guo LH, Yang SZ (2012) Treatment of enterococcus faecalis bacteria by a helium atmospheric cold plasma brush with oxygen addition. J Appl Phys 112:013304.

https://doi.org/10.1063/1.4732135

42.Koban I, Duske K, Jablonowski L, Schröeder K, Nebe B, Sietmann R, Weltmann KD, Hübner NO, Kramer A, Kocher T (2011) Atmospheric plasma enhances wettability and osteoblast spreading on dentin in vitro: proof-of-principle. Plasma Processes Polym 8:975-982.

https://doi.org/10.1002/ppap.201100030 
43.Schulein TM (1988) The smear layer on dentin. A status report for the American Journal of Dentistry. Am J Dent 1:264-270.

44.Guo X, Spencer P, Wang Y, Ye Q, Yao X, Williams K (2007) Effects of a solubility enhancer on penetration of hydrophobic component in model adhesives into wet demineralized dentin. Dent Mater 23:1473-1481.

https://doi.org/10.1016/i.dental.2006.12.003

45.Spencer $P$, Wang Y (2002) Adhesive phase separation at the dentin interface under wet bonding conditions. J Biomed Mater Res 62:447-456.

https://doi.org/10.1002/ibm.10364

46.Breschi M, Fabiani D, Sandrolini L, Colonna M, Sisti L, Vannini M, Mazzoni A, Ruggeri A, Pashley $\mathrm{DH}$, Breschi L (2012) Electrical properties of resin monomers used in restorative dentistry. Dent Mater 28:1024-1031.

https://doi.org/10.1016/i.dental.2012.05.009

47.Malacarne-Zanon J, Pashley DH, Agee KA, Foulger S, Alves MC, Breschi L, Cadenaro M, Garcia FP, Carrilho MR (2009) Effects of ethanol addition on the water sorption/solubility and percent conversion of comonomers in model dental adhesives. Dent Mater 25:1275-1284.

https://doi.org/10.1016/i.dental.2009.03.015

48.Yiu CK, King NM, Pashley DH, Suh BI, Carvalho RM, Carrilho MR, Tay FR (2004) Effect of resin hydrophilicity and water storage on resin strength. Biomaterials 25:5789-5796.

https://doi.org/10.1016/j.biomaterials.2004.01.026

49.Cardoso MV, de Almeida Neves A, Mine A, Coutinho E, Van Landuyt K, De Munck J, Van Meerbeek $B$ (2011) Current aspects on bonding effectiveness and stability in adhesive dentistry. Aust Dent J 56 Suppl 1:31-44.

https://doi.org/10.1111/j.1834-7819.2011.01294.x

50.Feitosa VP, Sauro S, Ogliari FA, Ogliari AO, Yoshihara K, Zanchi CH, Correr-Sobrinho L, Sinhoreti MA, Correr AB, Watson TF, Van Meerbeek B (2014) Impact of hydrophilicity and length of spacer chains on the bonding of functional monomers. Dent Mater 30:e317-323.

https://doi.org/10.1016/i.dental.2014.06.006

51.Dong X, Li H, Chen M, Wang Y, Yu Q (2015) Plasma treatment of dentin surfaces for improving self-etching adhesive/dentin interface bonding. Clin Plasma Med 3:10-16.

https://doi.org/10.1016/i.cpme.2015.05.002

52.Kim JH, Han GJ, Kim CK, Oh KH, Chung SN, Chun BH, Cho BH (2016) Promotion of adhesive penetration and resin bond strength to dentin using non-thermal atmospheric pressure plasma. Eur J Oral Sci 124:89-95.

https://doi.org/10.1111/eos.12246 


\section{FIGURE LEGENDS}

Figure 1. Experimental setup of NTAP plasma needle for dentin treatment. [Signal generator, amplifier and matching box are main components of the electrical circuit that supplies power to the NTAP. The oscilloscope and PC are used to control the power delivered to the NTAP].

Figure 2. Schematic of the contact angle analyzer setup and representative images of dentin disks with reference liquid drops. A) water on NTAP-treated dentin; B) water on phosphoric acid-treated dentin and C) water on untreated dentin.

Figure 3. Summary of the contact angle data for the three reference liquids on NTAP-treated dentin. [Same-type letters or symbols indicate statistical significance within each respective group $(p>0.05)$; $\mathrm{N}=5$ samples/group].

Figure 4. Surface free energy (SFE) of dentin following various treatments (meantstandard deviation). [Same-type letters or symbols indicate statistical significance within each respective group $(p>0.05)$ ].

Figure 5. Polar (Lewis base and Lewis acid) and apolar components of surface free energy on NTAPtreated and untreated, control dentin. The tested groups are presented on the $x$-axis [100\% He NTAP at $1 \mathrm{~W}, 2 \mathrm{~mm} ; 100 \%$ He NTAP at $1 \mathrm{~W}, 4 \mathrm{~mm}, 100 \% \mathrm{He}$ NTAP at $1 \mathrm{~W}, 8 \mathrm{~mm}$ etc.

Figure 6. Contact angle values (mean and standard deviation) for reference liquids and universal adhesives following different dentin treatments (group name: treatment_liquid). 'Control' denotes untreated dentin. Groups 'SBU' (Single Bond Universal) and 'CUB' (Clearfil Universal Bond) present contact angle values of the respective adhesive following the self-etch application protocol. [Groups connected with horizontal bars are not significantly different $(p>0.05)]$.

Figure 7. Surface free energy (SFE) and its polar (Lewis acid and Lewis base) and apolar components.

Figure 8. SEM micrographs of dentin following different treatments. All three NTAP treatments had the same parameters $\left(3 \mathrm{~W}\right.$ and $4 \mathrm{~mm}$ ) but differed in $\mathrm{O}_{2}$ feed. Dentin was acid etched for $15 \mathrm{~s}$. No treatment was performed in the control group. 
Table 1. Allocation of teeth to groups and subgroups according to treatments and reference liquids.

\begin{tabular}{|c|c|c|c|}
\hline Group & $\begin{array}{l}\text { Surface treatment } \\
\text { parameters }\end{array}$ & Reference liquid & Number of teeth \\
\hline \multirow{6}{*}{$\begin{array}{l}\text { NTAP } \\
100 \% \mathrm{He}\end{array}$} & $1 \mathrm{~W}, 2 \mathrm{~mm}$ & $\begin{array}{l}\text { Distilled water } \\
\text { Ethylene-glycol } \\
\text { Diiodomethane }\end{array}$ & $\begin{array}{l}5 \\
5 \\
5\end{array}$ \\
\hline & $1 \mathrm{~W}, 4 \mathrm{~mm}$ & $\begin{array}{l}\text { Distilled water } \\
\text { Ethylene-glycol } \\
\text { Diiodomethane }\end{array}$ & $\begin{array}{l}5 \\
5 \\
5\end{array}$ \\
\hline & $1 \mathrm{~W}, 8 \mathrm{~mm}$ & $\begin{array}{l}\text { Distilled water } \\
\text { Ethylene-glycol } \\
\text { Diiodomethane }\end{array}$ & $\begin{array}{l}5 \\
5 \\
5\end{array}$ \\
\hline & $3 \mathrm{~W}, 2 \mathrm{~mm}$ & $\begin{array}{l}\text { Distilled water } \\
\text { Ethylene-glycol } \\
\text { Diiodomethane }\end{array}$ & $\begin{array}{l}5 \\
5 \\
5\end{array}$ \\
\hline & $3 \mathrm{~W}, 4 \mathrm{~mm}$ & $\begin{array}{l}\text { Distilled water } \\
\text { Ethylene-glycol } \\
\text { Diiodomethane }\end{array}$ & $\begin{array}{l}5 \\
5 \\
5\end{array}$ \\
\hline & $3 \mathrm{~W}, 8 \mathrm{~mm}$ & $\begin{array}{l}\text { Distilled water } \\
\text { Ethylene-glycol } \\
\text { Diiodomethane }\end{array}$ & $\begin{array}{l}5 \\
5 \\
5\end{array}$ \\
\hline \multirow{4}{*}{$\begin{array}{c}\text { NTAP } \\
99 \% \mathrm{He}+1 \% \mathrm{O}_{2}\end{array}$} & $1 \mathrm{~W}, 2 \mathrm{~mm}$ & $\begin{array}{l}\text { Distilled water } \\
\text { Ethylene-glycol } \\
\text { Diiodomethane }\end{array}$ & $\begin{array}{l}5 \\
5 \\
5\end{array}$ \\
\hline & $1 \mathrm{~W}, 4 \mathrm{~mm}$ & $\begin{array}{l}\text { Distilled water } \\
\text { Ethylene-glycol } \\
\text { Diiodomethane }\end{array}$ & $\begin{array}{l}5 \\
5 \\
5\end{array}$ \\
\hline & $3 \mathrm{~W}, 2 \mathrm{~mm}$ & $\begin{array}{l}\text { Distilled water } \\
\text { Ethylene-glycol } \\
\text { Diiodomethane }\end{array}$ & $\begin{array}{l}5 \\
5 \\
5\end{array}$ \\
\hline & $3 \mathrm{~W}, 4 \mathrm{~mm}$ & $\begin{array}{l}\text { Distilled water } \\
\text { Ethylene-glycol } \\
\text { Diiodomethane }\end{array}$ & $\begin{array}{l}5 \\
5 \\
5\end{array}$ \\
\hline \multirow{4}{*}{$\begin{array}{c}\text { NTAP } \\
98.5 \% \mathrm{He}+1.5 \% \mathrm{O}_{2}\end{array}$} & $1 \mathrm{~W}, 2 \mathrm{~mm}$ & $\begin{array}{l}\text { Distilled water } \\
\text { Ethylene-glycol } \\
\text { Diiodomethane }\end{array}$ & $\begin{array}{l}5 \\
5 \\
5\end{array}$ \\
\hline & $1 \mathrm{~W}, 4 \mathrm{~mm}$ & $\begin{array}{l}\text { Distilled water } \\
\text { Ethylene-glycol } \\
\text { Diiodomethane }\end{array}$ & $\begin{array}{l}5 \\
5 \\
5\end{array}$ \\
\hline & $3 \mathrm{~W}, 2 \mathrm{~mm}$ & $\begin{array}{l}\text { Distilled water } \\
\text { Ethylene-glycol } \\
\text { Diiodomethane }\end{array}$ & $\begin{array}{l}5 \\
5 \\
5 \\
\end{array}$ \\
\hline & $3 \mathrm{~W}, 4 \mathrm{~mm}$ & $\begin{array}{l}\text { Distilled water } \\
\text { Ethylene-glycol } \\
\text { Diiodomethane }\end{array}$ & $\begin{array}{l}5 \\
5 \\
5\end{array}$ \\
\hline Phosphoric acid & $15 \mathrm{~s}$ & $\begin{array}{l}\text { Distilled water } \\
\text { Ethylene-glycol } \\
\text { Diiodomethane }\end{array}$ & $\begin{array}{l}5 \\
5 \\
5\end{array}$ \\
\hline Control group & No treatment & $\begin{array}{l}\text { Distilled water } \\
\text { Ethylene-glycol } \\
\text { Diiodomethane }\end{array}$ & $\begin{array}{l}5 \\
5 \\
5\end{array}$ \\
\hline \multirow{2}{*}{ ER_adhesive } & \multirow{2}{*}{$\begin{array}{l}\text { ER application } \\
\text { protocol }\end{array}$} & SBU & 5 \\
\hline & & CUB & 5 \\
\hline SE_adhesive & $\begin{array}{l}\text { SE application } \\
\text { protocol }\end{array}$ & SBU & 5 \\
\hline
\end{tabular}




\begin{tabular}{|c|c|c|c|}
\hline & & CUB & 5 \\
\hline NTAP_adhesive & $\begin{array}{c}98.5 \% \mathrm{He}+1.5 \% \mathrm{O}_{2} \\
3 \mathrm{~W}, 4 \mathrm{~mm}\end{array}$ & SBU \\
\hline NTAP_adhesive & $\begin{array}{c}98.5 \% \mathrm{He}+1.5 \% \mathrm{O}_{2} \\
3 \mathrm{~W}, 4 \mathrm{~mm}\end{array}$ & CUB & 5 \\
\hline \hline & $\begin{array}{c}\text { SEM } \\
\text { (control x 1 teeth; phosphoric acid x 1 teeth; }\end{array}$ \\
100\% He NTAP x 2 teeth; $99 \%$ He+1\% $\mathrm{O}_{2}$ NTAP x 2 teeth; \\
$98.5 \%$ He+1.5\% $\mathrm{O}_{2}$ NTAP x 2 teeth)
\end{tabular}

Abbreviations: NTAP - Non-thermal atmospheric plasma; SBU - Single Bond Universal; CUB - Clearfil Universal Bond; SEM - Scanning Electron Microscopy 
Table 2. Materials used in this study.

\begin{tabular}{|c|c|c|c|}
\hline $\begin{array}{c}\text { Material } \\
\text { (Code/Batch) }\end{array}$ & Manufacturer & Composition* & Application protocol \\
\hline \multirow{2}{*}{$\begin{array}{l}\text { Single Bond } \\
\text { Universal } \\
\text { (SBU/595822) }\end{array}$} & \multirow{2}{*}{$\begin{array}{l}\text { 3M ESPE, } \\
\text { St. Paul, MN, } \\
\text { USA }\end{array}$} & \multirow{2}{*}{$\begin{array}{l}\text { BisGMA }(15-25 \%) \text {, HEMA }(15- \\
25 \%) \text {, DMDMA }(5-15 \%) \text {, ethanol } \\
(10-15 \%) \text {, water }(10-15 \%) \text {, silane } \\
\text { treated silica }(5-15 \%), 1,10-\text { decanediol } \\
\text { methacrylated phosphates }(1-10 \%) \text {, } \\
\text { copolymer of acrylic and itaconic acid } \\
(1-5 \%) \text {, dimethylaminobenzoat } \\
(<2 \%) \text {, camphorquinone }(<2 \%) \text {, } \\
\text { DMAEMA }(<2 \%), \text { methylethylketone } \\
(<0.5 \%)\end{array}$} & $\begin{array}{l}\text { Etch-and-rinse: } \\
\text { Apply etchant for } 15 \mathrm{~s} \\
\text { Rinse for } 15 \text { sBlot-dry with a } \\
\text { cotton pellet } \\
\text { Apply SBU to dentin using a } \\
\text { disposable applicator and rub it } \\
\text { in for } 20 \mathrm{~s} \\
\text { Air dry with a gentle stream of } \\
\text { air for about } 5 \mathrm{~s}\end{array}$ \\
\hline & & & $\begin{array}{l}\text { Self-etch: } \\
\text { Rinse and dry } \\
\text { Apply SBU to dentin using a } \\
\text { disposable applicator and rub it } \\
\text { in for } 20 \mathrm{~s} \\
\text { Air dry with a gentle stream of } \\
\text { air for about } 5 \mathrm{~s}\end{array}$ \\
\hline \multirow{2}{*}{$\begin{array}{l}\text { Clearfil } \\
\text { Universal } \\
\text { Bond } \\
\text { (CUB/ } \\
\text { BN0010) }\end{array}$} & \multirow{2}{*}{$\begin{array}{l}\text { Kuraray } \\
\text { Noritake } \\
\text { Dental Inc., } \\
\text { Okayama, } \\
\text { Japan }\end{array}$} & \multirow{2}{*}{$\begin{array}{l}\text { BisGMA }(15-35 \%) \text {, HEMA }(10- \\
35 \%) \text {, ethanol }(<20 \%) \text {, 10-MDP, } \\
\text { hydrophilic aliphatic dimethacrylate, } \\
\text { colloidal silica, camphorquinone, } \\
\text { silane, accelerators, initiators, water }\end{array}$} & $\begin{array}{l}\text { Etch-and-rinse: } \\
\text { Apply etchant for } 15 \mathrm{~s} \\
\text { Rinse for } 15 \mathrm{~s} \\
\text { Blot-dry with a cotton pellet } \\
\text { Apply CUB } \\
\text { Dry the entire cavity by blowing } \\
\text { mild air more than } 5 \mathrm{~s}\end{array}$ \\
\hline & & & $\begin{array}{l}\text { Self-etch: } \\
\text { Rinse and dry } \\
\text { Apply CUB with a rubbing } \\
\text { motion to the entire cavity wall } \\
\text { with an applicator brush } \\
\text { Dry the entire cavity by blowing } \\
\text { mild air more than } 5 \mathrm{~s}\end{array}$ \\
\hline $\begin{array}{l}\text { Scotchbond } \\
\text { Universal } \\
\text { Etchant } \\
\text { (Acid/ } \underline{603390)}\end{array}$ & $\begin{array}{l}\text { 3M ESPE, } \\
\text { St. Paul, MN, } \\
\text { USA }\end{array}$ & $\begin{array}{l}\text { Water, phosphoric acid, synthetic } \\
\text { amorphous silica, fumed, crystalline } \\
\text { free, polyethylene glycol, aluminum } \\
\underline{\text { oxide }}\end{array}$ & $\frac{\text { Apply etchant for } 15 \mathrm{~s}}{\underline{\text { Rinse for } 15 \mathrm{~s}}}$ \\
\hline
\end{tabular}

*Manufacturers' data. Abbreviations: BisGMA - bisphenol A diglycidylmethacrylate, HEMA - 2hydroxyethyl methacrylate, DMDMA - decamethylenedimethacrylate, DMAEMA - dimethylaminoethyldimethacrylate, 10-MDP - 10-Methacryloyloxydecyl dihydrogen phosphate 


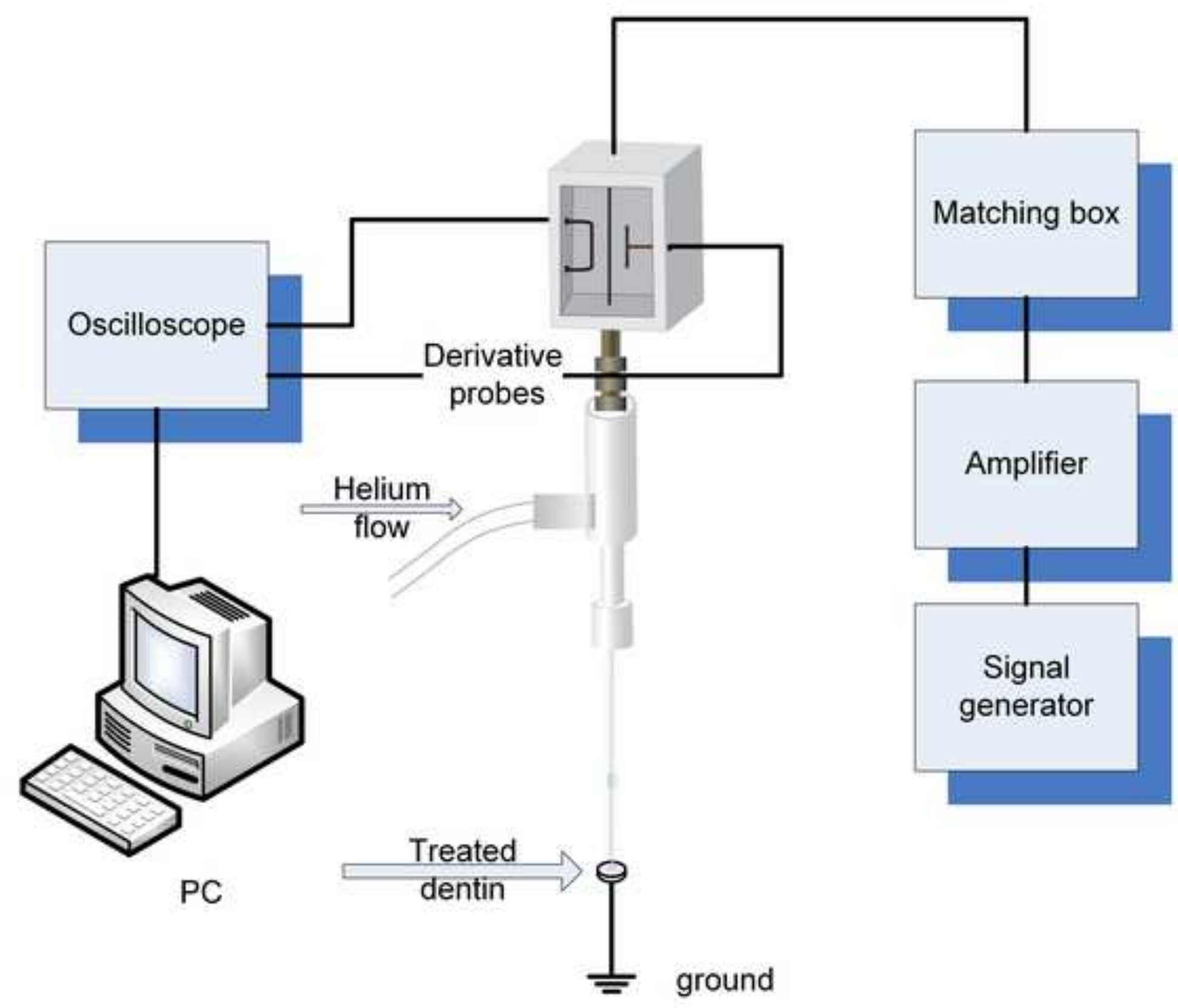



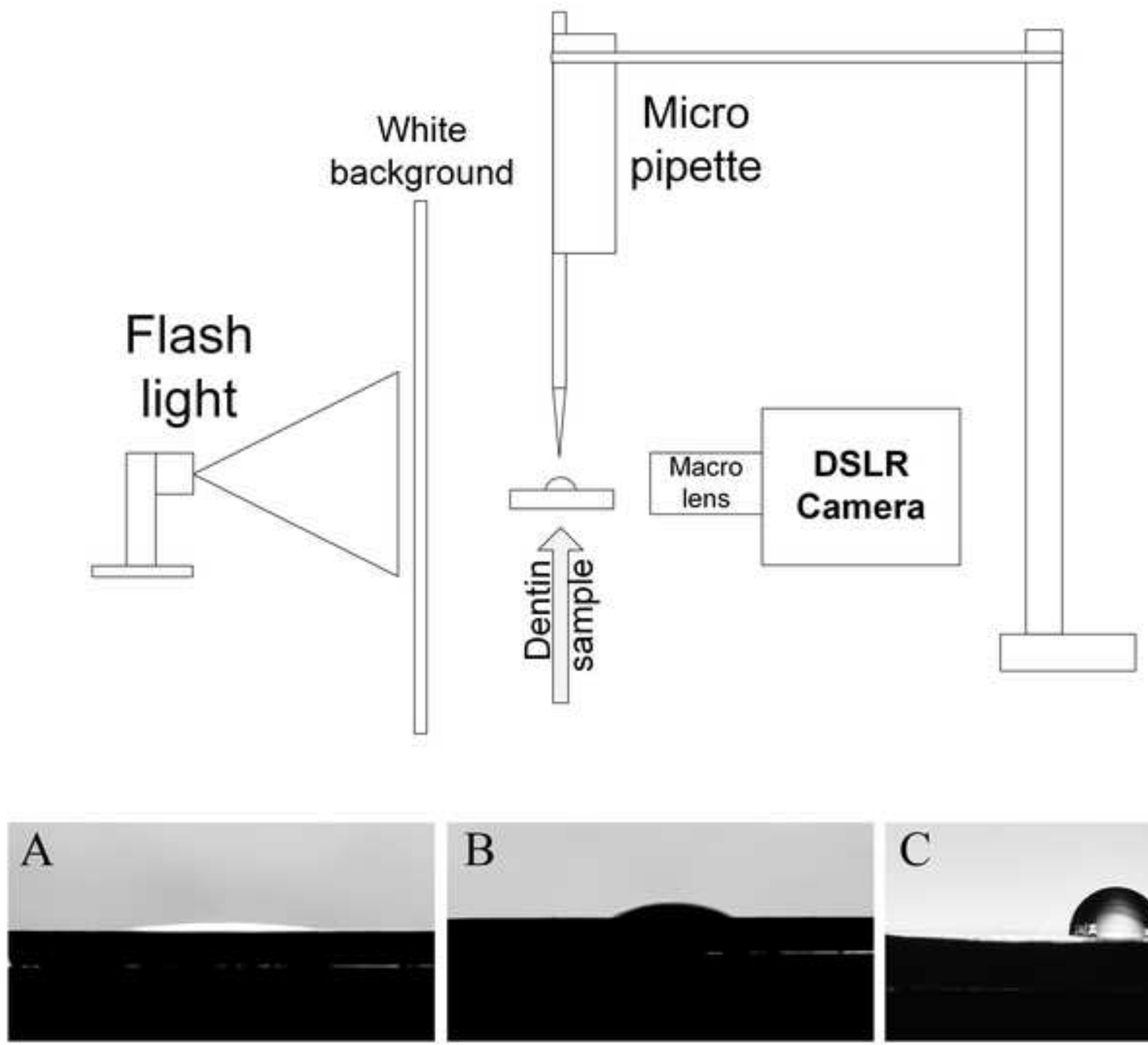

C

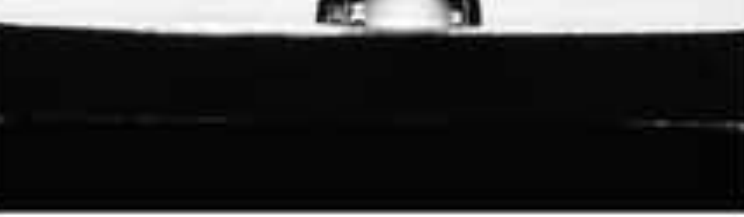



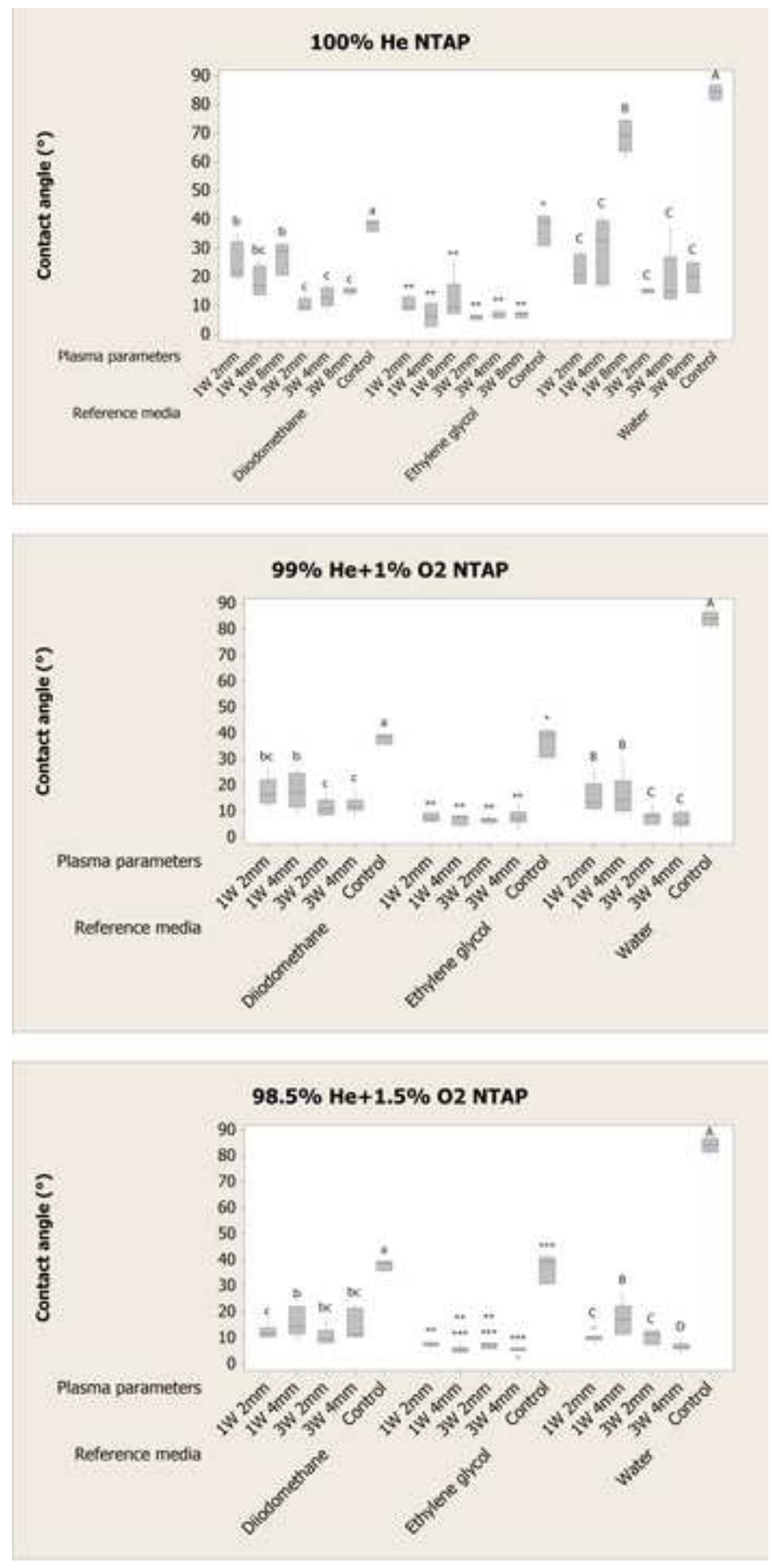


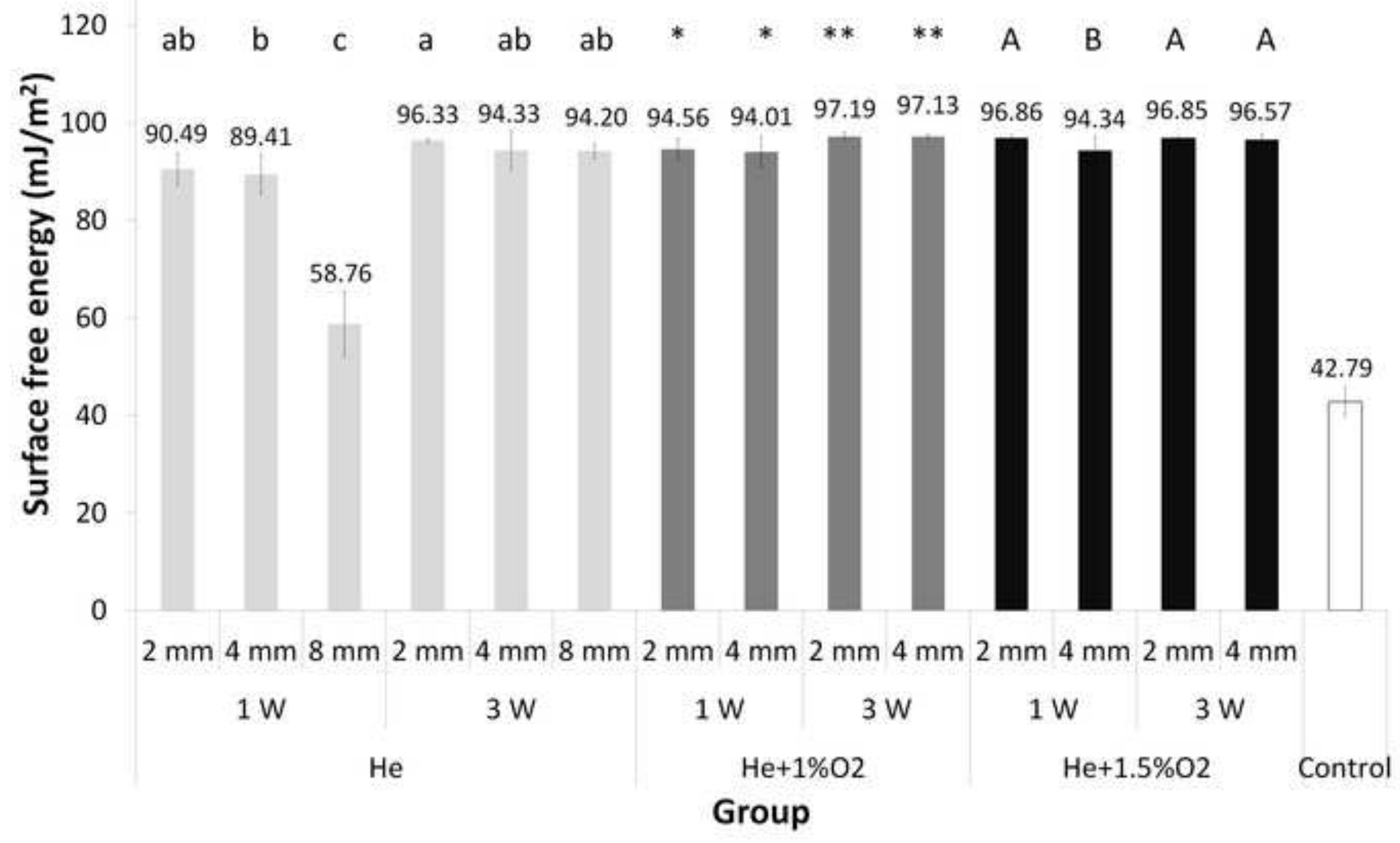




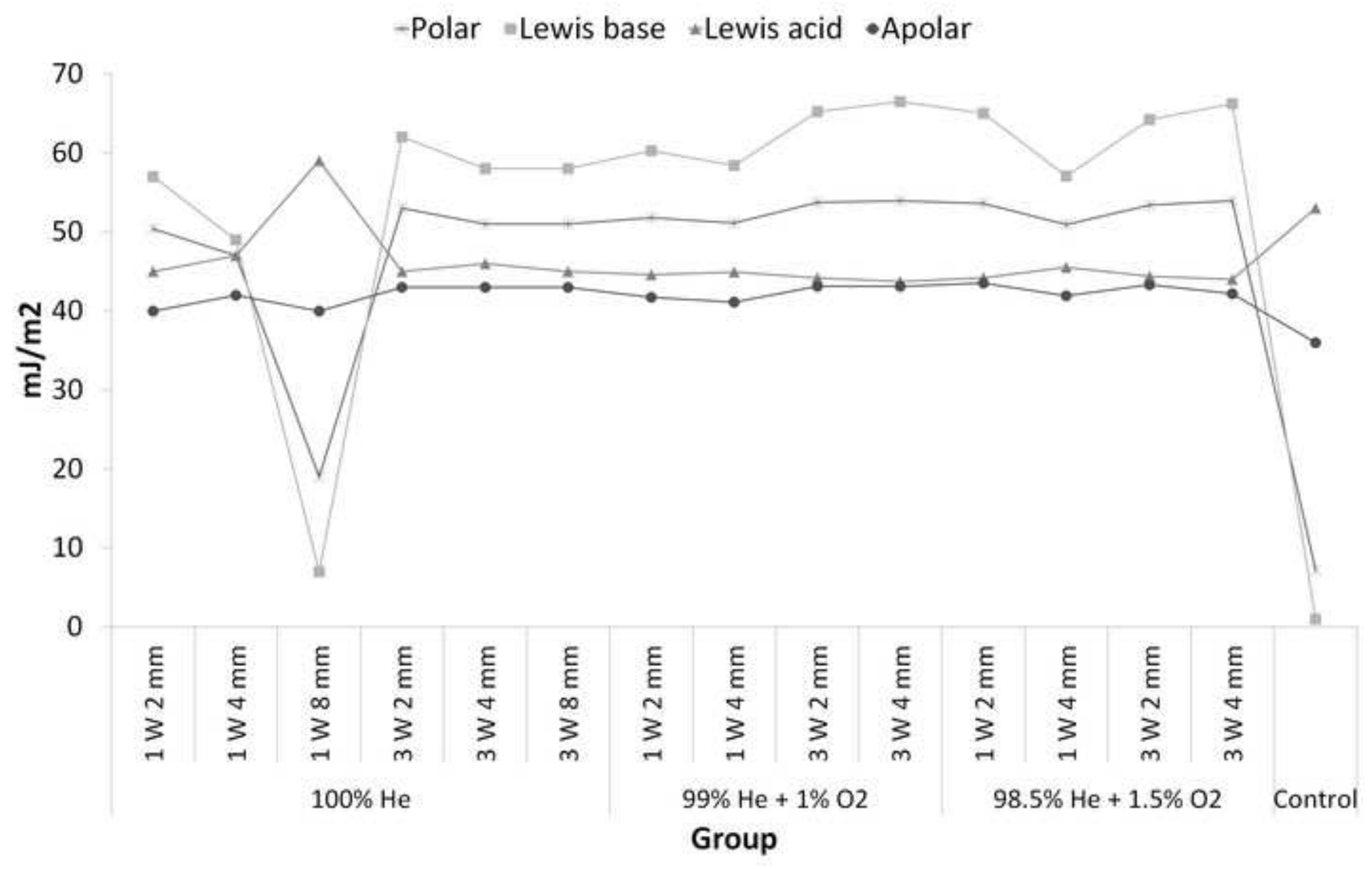




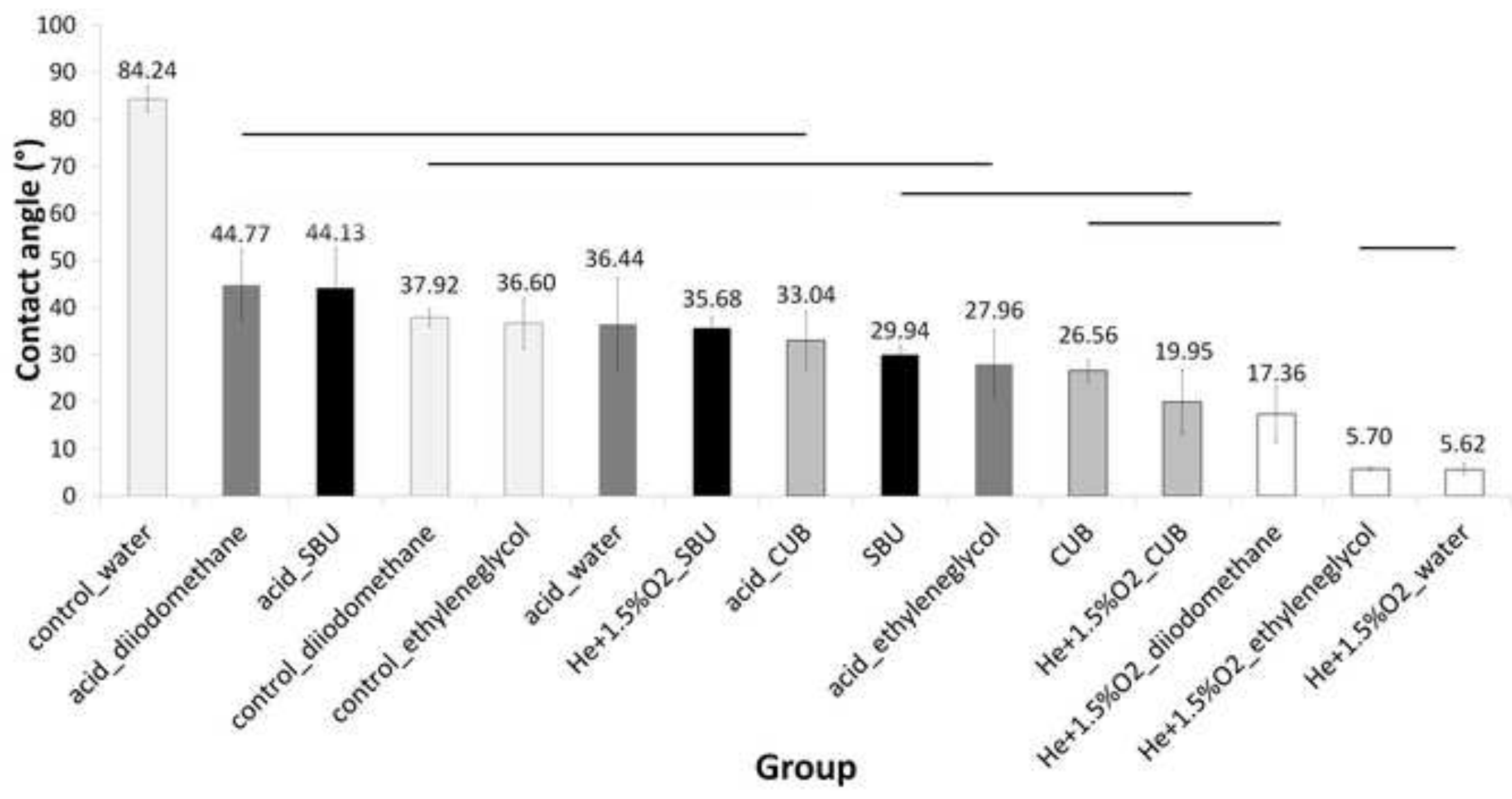




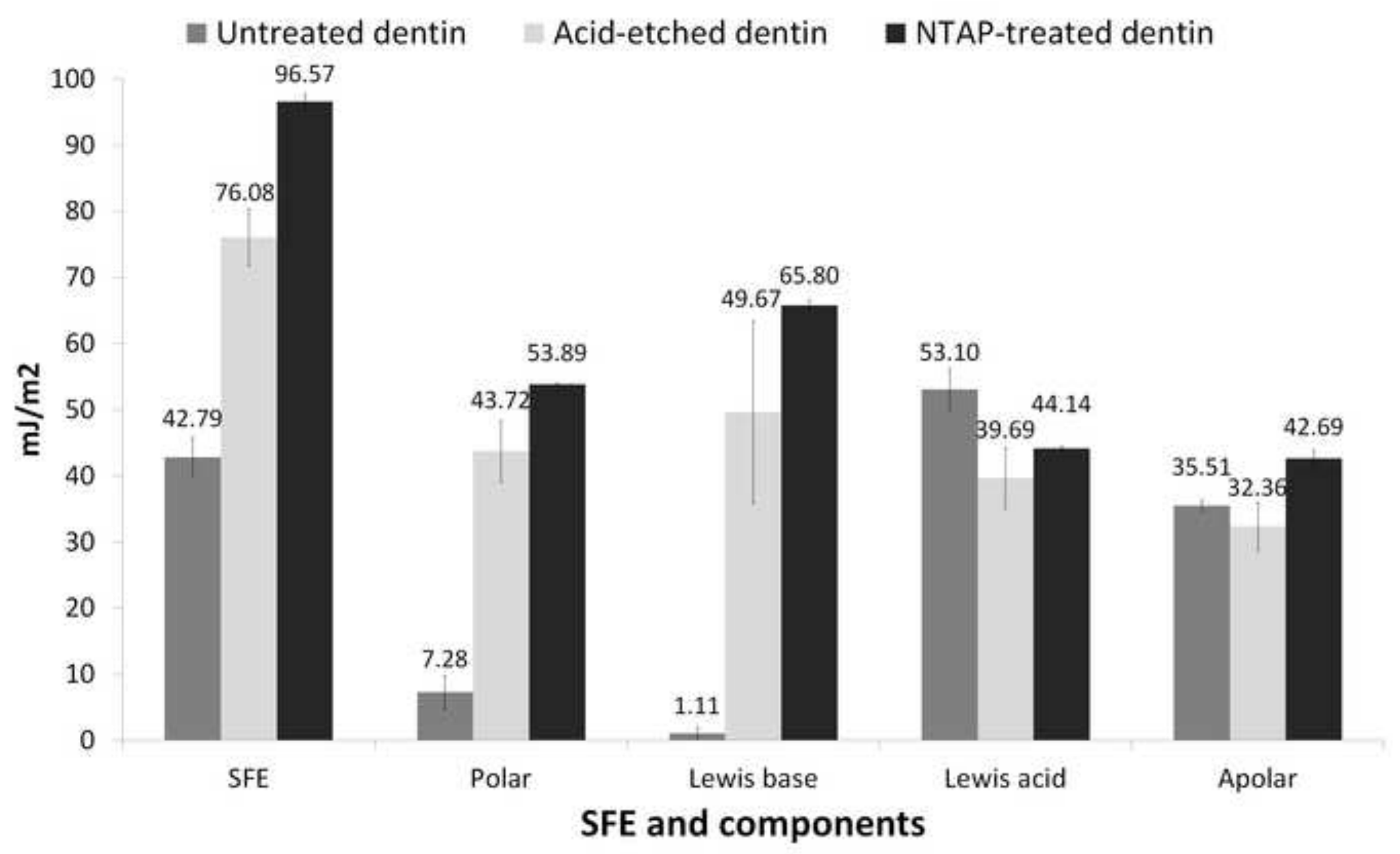




\section{Acid-etched dentin}

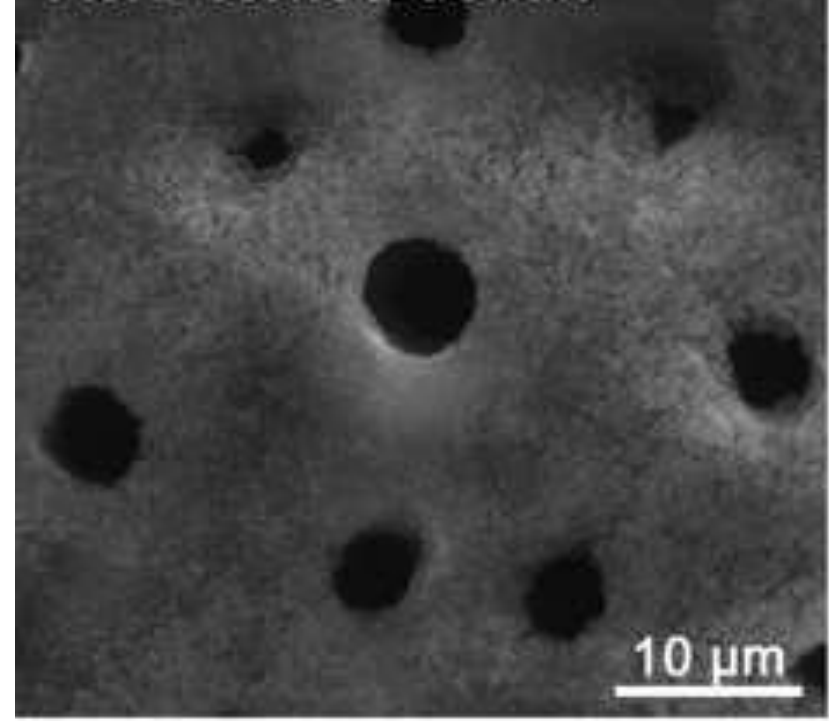

$100 \% \mathrm{He}$ NTAP

$98.5 \% \mathrm{He}+1.5 \%$ O2 NTAP

\section{Acid-etched dentin}

$99 \% \mathrm{He}+1 \%$ O2 NTAP

\section{Control}

